\title{
Indentifikasi Kerusakan Jalan Payakumbuh-Batusangkar Studi Kasus Jalan Barulak Tanjung Baruh - Tanjung Alam
}

\author{
Elvi Syamsuir ${ }^{1}$, Winda Armaya ${ }^{2}$, M. Irfan ${ }^{3}$ \\ Prodi Teknik Sipil, Sekolah Tinggi Teknologi Payakumbuh ${ }^{1,2,3}$ \\ Email: elvisyamsuir246@gmail.com ${ }^{1}$ \\ DOI: http://dx.doi.org/10.31869/rtj.v5i1.2729
}

\begin{abstract}
Jalan Raya dari Payakumbuh - Batusangkar termasuk Jalan Kota dan Kabupaten yang menghubungkan kota Payakumbuh, Kabupaten Lima Puluh Kota, Batusangkar dengan jarak tempuh sepanjang $36 \mathrm{~km}$. Untuk menuju Kota Batusangkar dari Payakumbuh ada beberapa daerah yang dilewati mulai dari Piladang - Barulak - Tanjung Alam - Salimpauang - Tabek Patah - Sungai Tarab. Kondisi beberapa jalan dari Piladang menuju Batusangkar mengalami kerusakan, lebih tepat daerah Barulak dengan Nagari Barulak Kecamatan Tanjung Baru menuju Tanjung Alam. Kerusakan ini dapat menimbulkan terjadinya kecelakaan pada pengguna jalan. Untuk menghindari dampak negatif yang ditimbulkan oleh kerusakan jalan tersebut, diperlukan lah penanganan khusus seperti perbaikan jalan, dimana metode perbaikan jalan harus mempertimbangkan kondis existing dengan mengumpulkan data terkait dengan kondisi jalan. Telah dilakukan penelitian tentang Indentifikasi Kerusakan Jalan Payakumbuh-Batusangkar (Studi Kasus Jalan Barulak Tanjumg Baruh - Tanjung Alam). Penelitian ini dilakukan dengan tahapan (1) Asessment awal, yaitu survey awal, survey yang dilakukan untuk mengetahui kondisi jalan secara umum (2) Visual Asessment, melakukan pengecekan kondisi jalan dengan cara melihat langsung kerusakan-kerusakan yang ada pada jalan serta membagi kerusakan tersebut dalam beberapa jenis/ komponen. (3) Technical Asessment, Pengukuran langsung yang dilakukan terhadap kerusakan-kerusakan jalan untuk mengambil dimensi serta luas kerusakan. Hasil yang didapatkan pada saat penelitian ini dilakukan dan sampai tahap pengolahan data menunjukkan bahwa jalan Payakumbuh-Batusangkar (Barulak Tanjung Baruh - Tanjung Alam) dalam kondisi kerusakan rata-rata high (tinggi) kecuali retak pinggir dengan tingkat kerusakan low. Pada Ruas Jalan Barulak Tanjung Alam STA $0+000$ sampai STA $0+800$ ditemukan jenis kerusakan pada perkerasaan jalan yang paling jauh besar adalah retak memanjang dengan luas kerusakan $61,5 \mathrm{~m}^{2}$ dan terkecil adalah retak pinggir dengan luas kerusakan $1 \mathrm{~m}^{2}$. Penelitian ini menghasilkan suatu sarankan pada pemerintah terkait supaya kerusakan yang terjadi pada ruas jalan Barulak Tanjung Baruh- Tanjung Alam tidak menjadi lebih parah maka perlu dilakukan tindakan perbaikan pada bagian-bagian yang rusak sehingga tidak menimbukan kerusakan yang lebih parah, serta terciptanya keamanan dan kenyamanan pengendara.
\end{abstract}

Keywords: Identifikasi Kerusakan, Jalan Raya, dan Transportasi

\section{PENDAHULUAN}

Transportasi adalah salah satu kebutuhan dan kepentingan keseluruhan manusia yang disebabkan oleh adanya suatu sistem pergerakan atau perpindahan objek, baik berupa manusia atau pun barang dari suatu tempat asal ketempat perpindahan tujuan yang dikehendaki (Lah, 2014), (Putra, 2019), (Riski, dkk, 2018). Transportasi memegang peranan penting dalam pelaksanaan pembangunan dan pengembangan daerah disegala bidang. Sehingga diperlukan suatu perencanaan jalan agar benar-benar berfungsi sebagai sarana transportasi (Kadarisman, dkk, 2016), (Arliman, 2018), (Rodji, dkk, 2019). Jalan secara khusus berdasarkan undang-Undang RP No. 38 Tahun2004 adalah, prasarana transportasi darat yang meliputi segala bagian jalan, termasuk bangunan pelengkap dan perlengkapannya yang diperuntukan bagi lalu lintas, yang berada pada permukaan tanah (Handayani, dkk., 2020), (Adwang, 2020), (Alelo, dkk., 2020). Maka dari itu diperlukanlah jalan yang aman dan nyaman untuk dilalui kendaraan. Jalan Raya dari Payakumbuh - Batusangkar termasuk Jalan Kota dan Kabupaten yang menghubungkan kota Payakumbuh, Kabupaten Lima Puluh Kota, Batusangkar dengan jarak tempuh sepanjang $36 \mathrm{~km}$. Untuk menuju Kota Batusangkar dari Payakumbuh ada beberapa daerah yang dilewati mulai dari Piladang Barulak - Tanjung Alam - Salimpauang Tabek Patah - Sungai Tarab. Kondisi beberapa 
jalan dari Piladang menuju Batusangkar mengalami kerusakan, lebih tepat daerah Barulak dengan Nagari Barulak Kecamatan Tanjung Baru menuju Tanjung Alam. Jalan Barulak Kecamatan Tanjung Baruh menuju Tanjung Alam dari pengamatan lapangan banyak nya jalan yang sudah rusak. Dari Nagari Barulak- Tanjung Alam jalan dalam kondisi rusak sehingga membuat kurang nyamannya saat berkendara. Lubang-lubang besar, keretakan serta pelepasan butiran pada permukaan jalan dapat mengganggu kenyamanan dan menyulitkan pengguna jalan raya dari Batusangkar yang hendak menuju kota Payakumbuh dan Pekanbaru. Kerusakan ini dapat menimbulkan terjadinya kecelakaan pada pengguna jalan. Untuk menghindari dampak negatif yang ditimbulkan oleh kerusakan jalan tersebut, diperlukan lah penanganan khusus seperti perbaikan jalan, dimana metode perbaikan jalan harus mempertimbangkan kondisi existing dengan mengumpulkan data terkait dengan kondisi jalan. Hal ini yang melatar belakangi penulis melakukan penelitian dengan judul' Identifikasi Kerusakan Jalan Payakumbuh Batusangkar (Studi Kasus Jalan Barulak Tanjung Baruh- Tanjung Alam).

\section{METODE PENELITIAN}

Penelitian ini dilakukan dalam beberapa tahapan seperti yang disajikan pada Gambar 1. Metode pengumpulan data sebagai berikut: (1) Asessment awal, yaitu survey awal, survey yang dilakukan untuk mengetahui kondisi jalan secara umum (2) Visual Asessment, melakukan pengecekan kondisi jalan dengan cara melihat langsung kerusakankerusakan yang ada pada jalan serta membagi kerusakan tersebut dalam beberapa jenis/ komponen. (3) Technical Asessment, Pengukuran langsung yang dilakukan terhadap kerusakan-kerusakan jalan untuk mengambil dimensi serta luas kerusakan, lokasi tempat penelitian ditunjukkan pada Gambar 2.

Setelah didapat semua dimensi kerusakan maka akan dihitung Luas total jenis kerusakan (Ad) dan Luas total unit segmen (As). Selanjutnya menghitung nilai tingkat kerusakan dari Low severity, Medium severity dan High severity. Setelah didapat tingkat kerusakan baru ditentukan nilai Density.

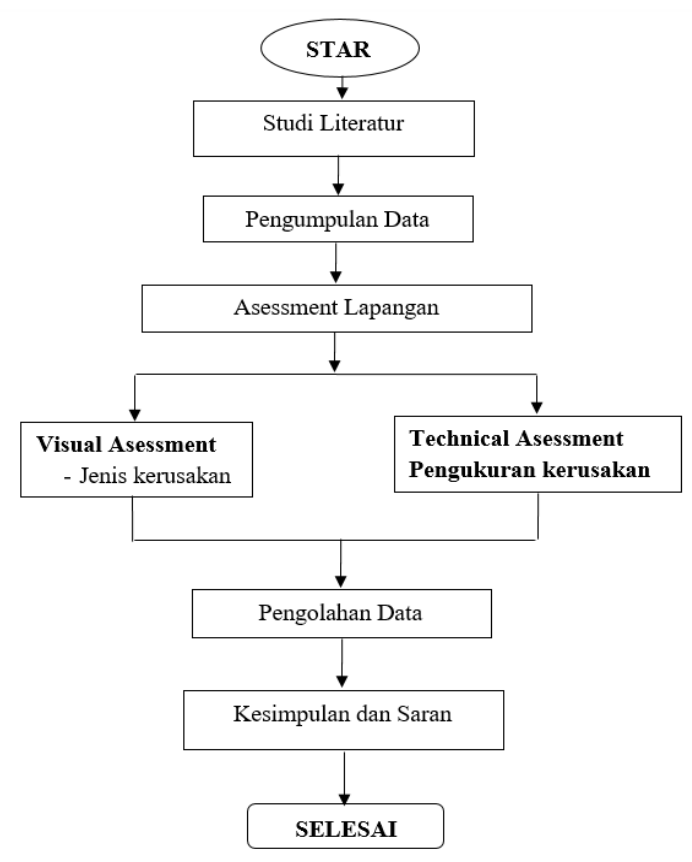

Gambar 1. Diagram alir penelitian

Metoda pengukuran kerusakan yang digunakan untuk penelitian ini sebagai berikut: (1) Mempersiapkan peralatanperalatan serta perlengkapan yang diperlukan, seperti meteran, spidol, kayu patok, dan cat. (2) Menentukan titik-titik kerusakan dan memberi tanda. (3) Pengukuran langsung yang dilakukan terhadap kerusakan-kerusakan jalan untuk mengambil dimensi mulai dari lebar, panjang, dalam atau tinggi kerusakan.

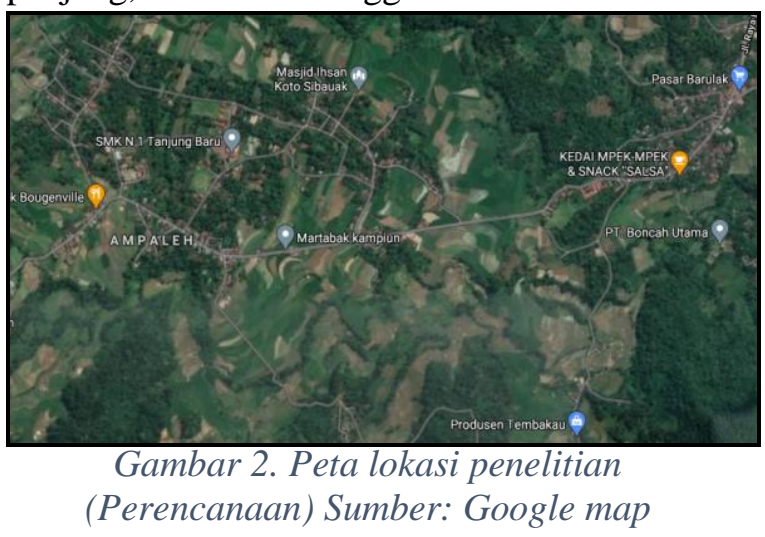




\section{HASIL DAN PEMBAHASAN}

Ruas jalan Payakumbuh Batusangkar merupakan Jalan Kota / Kabupaten yang mempunyai frekuensi lalu lintas tinggi. Kerusakan-kerusakan yang terjadi ada dibeberapa titik, tentu akan berpengaruh pada keamanan dan kenyamanan pemakai jalan. Kerusakan jalan dapat disebabkan oleh beberapa faktor, diantaranya air, perubahan suhu, cuaca, temperatur udara, material konstruksi perkerasan, kondisi tanah dasar yang tidak stabil, proses pemadatan di atas lapisan tanah dasar yang kurang baik atau muatan kendaraan berat yang melebihi kapasitas serta volume kendaraan yang semakin meningkat.

Lapisan perkerasan jalan dari Nagari Barulak Tanjung Baruh menuju Tanjung Alam berdasarkan hasil survey. Ada beberapa jenis kerusakan pada perkerasan lentur yang terjadi diantaranya :

1. Amblas adalah penurunan perkerasan yang terjadi pada area terbatas yang mungkin dapat diikuti dengan retakan. Kerusakan ini dapat terdeteksi dengan air yang tergenang , kemudian meresap kedalam lapisan permukaan yang akhirnya menimbulkan luabang.

2. Tambalan adalah permukaan perkerasan yang telah diganti menjadi baru untuk memperbaiki perkerasan yang ada.

3. Lubang adalah lekukan permukaan perkerasan akibat hilangnya lapisan aus dan material lapis pondasi. Lubang biasanya terjadi akibat galian utilitas atau tambalan di area perkerasan yang telah ada.

4. Retak kulit buaya adalah serangkaian retak memanjang paralel yang membentuk banyak sisi menyerupai kulit buaya.

5. Retak berbentuk memanjang pada perkerasan jalan, dapat terjadi dalam bentuk tunggal atau berderet yang sejajar dan kadang-kadang sedikit bercabang. Retak melintang merupakan retak tunggal (tidak bersambungan satu sama lain) yang melintang perkerasan.

6. Pelapukan dan pelepasan butir adalah disintegrasi permukaan perkerasan aspal melalui pelepasan partikel agregat yang berkelanjutan, berawal dari permukaan perkerasan menuju ke bawah atau dari tepi ke dalam.

7. Penurunan bahu jalan adalah kerusakan yang terjadi akibat adanya beda ketinggian antara permukaan perkerasan dengan permukaan bahu/tanah sekitarnya.

8. Cekungan adalah kerusakan yang disebabkan oleh penumpukan material pada suatu celah jalan yang diakibatkan oleh volume lalu lintas.

9. Retak Pinggir adalah kerusakan yang terjadi pada pertemuan tepi permukaan perkerasan dengan tanah sekitarnya.

Hasil perhitungan luas kerusakan pada jalan Barulak - Tanjung Alam (STA 0+000 sampai 0+800) ditampilkan pada Tabel 1.

Tabel 1. Hasil Perhitungan luas kerusakan pada STA $0+000$ sampai $0+800$

\begin{tabular}{|c|c|c|c|c|c|}
\hline \multirow[b]{2}{*}{ STA } & \multirow[b]{2}{*}{ Kerusakan } & \multicolumn{4}{|c|}{ Luas Kerusakan } \\
\hline & & $\begin{array}{c}\mathrm{P} \\
(\mathrm{m})\end{array}$ & $\begin{array}{c}\mathrm{L} \\
(\mathrm{m})\end{array}$ & $\begin{array}{c}\mathrm{D} \\
(\mathrm{m})\end{array}$ & $\begin{array}{c}\mathrm{A} \\
\left(\mathrm{m}^{2}\right)\end{array}$ \\
\hline $\begin{array}{c}0+500 \\
- \\
0+600\end{array}$ & Amblas & 16 & 2 & & 32 \\
\hline $\begin{array}{c}0+526 \\
- \\
0+528\end{array}$ & Tambalan & 2 & 1 & & 2 \\
\hline $\begin{array}{c}0+065 \\
- \\
0+080\end{array}$ & Lubang & 15 & 0,08 & 0,45 & 2,39 \\
\hline $\begin{array}{c}0+346 \\
- \\
0+360 \\
\end{array}$ & $\begin{array}{c}\text { Retak kulit } \\
\text { buaya }\end{array}$ & 14 & 1,5 & & 21 \\
\hline $\begin{array}{c}0+391 \\
- \\
0+432\end{array}$ & $\begin{array}{c}\text { Retak } \\
\text { Memanjan } \\
\text { g }\end{array}$ & 41 & 1,5 & & 61,5 \\
\hline $\begin{array}{c}0+000 \\
- \\
0+100 \\
\end{array}$ & $\begin{array}{c}\text { Lubang } \\
\text { Memanjan } \\
\text { g }\end{array}$ & 100 & 0,08 & 0,5 & 19,63 \\
\hline $\begin{array}{c}0+296 \\
- \\
0+330\end{array}$ & $\begin{array}{l}\text { Pelapukan } \\
\text { dan } \\
\text { pelepasan } \\
\text { butir }\end{array}$ & 34 & & & 34 \\
\hline $\begin{array}{c}0+095 \\
- \\
0+124\end{array}$ & $\begin{array}{l}\text { Penurunan } \\
\text { bahu jalan }\end{array}$ & 29 & 0,8 & & 23,20 \\
\hline $\begin{array}{c}0+715 \\
- \\
0+729\end{array}$ & Cekungan & 14 & 4 & & 56 \\
\hline $\begin{array}{c}0+526 \\
- \\
0+528 \\
\end{array}$ & $\begin{array}{c}\text { Retak } \\
\text { Pinggir }\end{array}$ & 2 & 0,5 & & 1 \\
\hline
\end{tabular}


Dimana $: \mathrm{AD}=$ Luas total dari satu jenis perkerasan untuk setiap tingkat keparahan kerusakan $\left(\mathrm{m}^{2}\right)$. AS $=$ Luas total unit sampel $\left(\mathrm{m}^{2}\right)$. Perhitungan selanjutnya ditampilkan Pada Tabel 2.

Pada Ruas Jalan Barulak Tanjung Alam STA $0+000$ sampai STA $0+800$ ditemukan jenis kerusakan pada perkerasaan jalan yaitu kerusakan amblas (depression) dengan tingkat kerusakan high, Tambalan dan galian utilitas (patching and utility cut patching) dengan tingkat kerusakan medium, lubang (potholes) dengan tingkat kerusakan high, retak kulit buaya (alligator cracking) dengan tingkat kerusakan high, retak memanjang dengan tingkat kerusakan high, lubang memanjang dengan tingkat kerusakan high, pelapukan dan pelepasan butiran dengan tingkat kerusakan high, penurunan bahu jalan dengan tingkat kerusakan high, cekungan dengan tingkat kerusakan high, dan retak pinggir dengan tingkat kerusakan low.

Tabel 2. Perhitungan kerapatan (Density)

\begin{tabular}{|c|c|c|c|c|}
\hline \multirow[b]{2}{*}{ STA } & \multirow[b]{2}{*}{ Kerusakan } & \multicolumn{3}{|c|}{ Luas Kerusakan \% } \\
\hline & & $\mathrm{AD}$ & AS & $\begin{array}{c}\text { Density } \\
(\mathrm{AD} / \mathrm{AS} \\
=\%)\end{array}$ \\
\hline $\begin{array}{c}0+500- \\
0+600\end{array}$ & Amblas & 32 & $\begin{array}{l}4 x \\
800 \\
\end{array}$ & 1,00 \\
\hline $\begin{array}{c}0+526- \\
0+528\end{array}$ & Tambalan & 2 & $\begin{array}{l}4 x \\
800\end{array}$ & 0,0625 \\
\hline $\begin{array}{c}0+065- \\
0+080\end{array}$ & Lubang & 2,39 & $\begin{array}{l}4 \mathrm{x} \\
800 \\
\end{array}$ & 0,0747 \\
\hline $\begin{array}{c}0+346- \\
0+360\end{array}$ & $\begin{array}{c}\text { Retak kulit } \\
\text { buaya }\end{array}$ & 21 & $\begin{array}{l}4 x \\
800\end{array}$ & 0,6562 \\
\hline $\begin{array}{c}0+391- \\
0+432\end{array}$ & $\begin{array}{c}\text { Retak } \\
\text { Memanjang }\end{array}$ & 61,5 & $\begin{array}{l}4 \times \\
800\end{array}$ & 1,9219 \\
\hline $\begin{array}{c}0+000- \\
0+100\end{array}$ & $\begin{array}{c}\text { Lubang } \\
\text { Memanjang }\end{array}$ & 19,63 & $\begin{array}{l}4 \mathrm{x} \\
800\end{array}$ & 0,6134 \\
\hline $\begin{array}{c}0+296- \\
0+330\end{array}$ & $\begin{array}{l}\text { Pelapukan } \\
\text { dan } \\
\text { pelepasan } \\
\text { butir }\end{array}$ & 34 & $\begin{array}{l}4 x \\
800\end{array}$ & 1,0625 \\
\hline $\begin{array}{c}0+095- \\
0+124\end{array}$ & $\begin{array}{l}\text { Penurunan } \\
\text { bahu jalan }\end{array}$ & 23,20 & $\begin{array}{l}4 x \\
800\end{array}$ & 0,7250 \\
\hline $\begin{array}{c}0+715- \\
0+729 \\
\end{array}$ & Cekungan & 56 & $\begin{array}{l}4 \mathrm{x} \\
800\end{array}$ & 1,75 \\
\hline $\begin{array}{c}0+526- \\
0+528\end{array}$ & $\begin{array}{c}\text { Retak } \\
\text { Pinggir }\end{array}$ & 1 & $\begin{array}{l}4 x \\
800 \\
\end{array}$ & 0,0312 \\
\hline
\end{tabular}

Pada Ruas Jalan Barulak Tanjung Alam STA $0+000$ sampai STA $0+800$ ditemukan jenis kerusakan pada perkerasaan jalan yaitu kerusakan amblas (depression) dengan luas kerusakan $32 \mathrm{~m}^{2}$, Tambalan dan galian utilitas (patching and utility cut patching) dengan luas kerusakan $2 \mathrm{~m}^{2}$, lubang (potholes) dengan luas kerusakan 2,39 $\mathrm{m}^{2}$, retak kulit buaya (alligator cracking) dengan luas kerusakan $21 \mathrm{~m}^{2}$, retak memanjang dengan luas kerusakan $61,5 \mathrm{~m}^{2}$, lubang memanjang dengan luas kerusakan 19,63 $\mathrm{m}^{2}$, pelapukan dan pelepasan butiran dengan luas kerusakan $34 \mathrm{~m}^{2}$, penurunan bahu jalan dengan luas kerusakan 23,2 $\mathrm{m}^{2}$, cekungan dengan luas kerusakan $56 \mathrm{~m}^{2}$, dan retak pinggir dengan luas kerusakan $1 \mathrm{~m}^{2}$. Pada Ruas Jalan Barulak Tanjung Alam STA $0+000$ sampai STA $0+800$ ditemukan jenis kerusakan pada perkerasaan jalan yaitu kerusakan amblas (depression) dengan kerapatan (density) 1\%, Tambalan dan galian utilitas (patching and utility cut patching) dengan kerapatan (density) 0,0625\%, lubang (potholes) dengan kerapatan (density) $0,0747 \%$, retak kulit buaya (alligator cracking) dengan kerapatan (density) 0,6562\%, retak memanjang dengan kerapatan (density) $1,9219 \%$, lubang memanjang dengan kerapatan (density) 0,6134\%, pelapukan dan pelepasan butiran dengan kerapatan (density) $1,0625 \%$, penurunan bahu jalan dengan kerapatan (density) $0,7250 \%$, cekungan dengan $1,75 \%$, dan retak pinggir dengan kerapatan (density) 0,0312\%.

\section{PENUTUP}

Berdasarkan hasil yang telah didapatkan dan dilakukan pembahasan, maka dapat kita simpulkan hal-hal sebagai berikut: (1) Pada saat penelitian ini dilakukan dan sampai tahap pengolahan data didapatkan kesimpulan bahwa jalan Payakumbuh-Batusangkar (Barulak Tanjung Baruh - Tanjung Alam) dalam kondisi kerusakan rata-rata high (tinggi) kecuali retak pinggir dengan tingkat kerusakan low. (2) Pada Ruas Jalan Barulak Tanjung Alam STA $0+000$ sampai STA $0+800$ ditemukan jenis kerusakan pada perkerasaan jalan yang paling jauh besar adalah retak memanjang dengan luas kerusakan 61,5 $\mathrm{m}^{2}$ dan terkecil adalah retak pinggir dengan luas kerusakan $1 \mathrm{~m}^{2}$.

Untuk melengkapi hasil dari penelitian ini disarankan pada peneliti berikutnya untuk penelitian lanjutan tentang nilai kondisi 
perkerasan jalan berdasarkan PCI serta standar penanganan kondisi kerusakan jalan Barulak Tanjung Baruh- Tanjung Alam. Disarankan agar kerusakan yang terjadi pada ruas jalan Barulak Tanjung Baruh- Tanjung Alam tidak menjadi lebih parah maka perlu dilakukan tindakan perbaikan pada bagian-bagian yang rusak sehingga tidak menimbukan kerusakan yang lebih parah, serta terciptanya keamanan dan kenyamanan pengendara.

\section{UCAPAN TERIMAKASIH}

Terimakasih kepada Yayasan Pendidikan Tinggi Payakumbuh (YPTP) yang telah memberikan bantuan penelitian mandiri melalui skema penelitian mandiri yang disediakan oleh PPPM Sekolah Tinggi Teknologi Payakumbuh. Terimakasih penulis ucapkan kepada mahasiswa Program Studi Teknik Sipil yang telah banyak membantu dalam proses pengambilan data di Lapangan. Ucapan Terimakasih kepada Bapak Dr. Ramacos Fardela, S.Si., M.Sc. yang telah banyak membantu dalam proses penelitian sampai dengan publikasi ilmiah.

\section{DAFTAR PUSTAKA}

Adwang, J. (2020). Analisa Uji Laik Fungsi Jalan (ULFJ) Pada Ruas Jalan Nasional Tumora (Bts. Kab. Parimo)-Tambrana Nomor Ruas $31 \mathrm{Km} .157+800 \mathrm{sd} \mathrm{Km}$. $168+\quad 000 \quad$ Provinsi Sulawesi Tengah. TEKNO, 18(74).

Alelo, I. J., Manoppo, M. R., \& Sendow, T. K. (2020). Uji Laik Fungsi Jalan Secara Teknis Pada Ruas Jalan CitralandInterchange Manado Bypass. Jurnal Sipil Statik, 8(2).

Arliman, L. (2018). Peran Investasi dalam Kebijakan Pembangunan Ekonomi Bidang Pariwisata di Provinsi Sumatera Barat. Kanun Jurnal Ilmu Hukum, 20(2), 273-294.

Handayani, F., Fahriana, N., \& Basrin, D. (2020). Studi Kajian Profil Jalan Tm. Bahrum Kota Langsa-Langsa. Jurnal Media Teknik Sipil Samudra, 1(2), 5-12.

Kadarisman, M., Gunawan, A., \& Ismiyati, I. (2016). Kebijakan Manajemen Transportasi darat dan dampaknya terhadap perekonomian masyarakat di Kota Depok. Jurnal Manajemen Transportasi \& Logistik, 3(1), 41-58.
Lah, A. (2014). Analisa Tanah Dasar (Subgrade) Pada Ruas Jalan Sangkulirang-Simpang Kaliorang Dikabupaten Kutai Timur. Kurva S Jurnal Mahasiswa, 4(1), 366-375.

Putra, M. Y. (2019). Perencanaan Jalan Anjir Serapat-Palampai I Dengan Menggunakan Perkerasan Kaku (Rigid Pavement) Kapuas, Kalimantan Tengah (Doctoral Dissertation, University Of Muhammadiyah Malang).

Riski, M. S., \& Putra, T. S. (2018). Peningkatan Ruas Jalan Dengok-Bts. Kabupaten Ponorogo/Trenggalek STA 16+ 00019+ 000 Provinsi Jawa Timur Dengan Menggunakan Struktur Perkerasan Kaku (Doctoral dissertation, Institut Teknologi Sepuluh Nopember).

Rodji, A. P., \& Rohayani, S. (2019). Analisis Perencanaan Peningkatan Jalan Menggunakan Perkerasan Kaku Pada Ruas Jalan Kosambi-Telagasari Kecamatan Klari Kabupaten Karawang. Prosiding Semnastek 2019, l(1). 